\title{
Transmission of Multilevel 60 Gbit/s Polarization Multiplexed RZ-D8PSK using only 10
} Gbit/s equipment

\author{
Jensen, Jesper Bevensee; Tokle, Torger; Peucheret, Christophe; Jeppesen, Palle
}

\section{Published in:}

Conference on Optical Fiber Communication and the National Fiber Optic Engineers Conference, 2007. OFC/NFOEC 2007.

Link to article, DOI:

10.1109/OFC.2007.4348907

Publication date:

2007

Document Version

Publisher's PDF, also known as Version of record

Link back to DTU Orbit

Citation (APA):

Jensen, J. B., Tokle, T., Peucheret, C., \& Jeppesen, P. (2007). Transmission of Multilevel 60 Gbit/s Polarization Multiplexed RZ-D8PSK using only $10 \mathrm{Gbit} / \mathrm{s}$ equipment. In Conference on Optical Fiber Communication and the National Fiber Optic Engineers Conference, 2007. OFC/NFOEC 2007. IEEE. https://doi.org/10.1109/OFC.2007.4348907

\section{General rights}

Copyright and moral rights for the publications made accessible in the public portal are retained by the authors and/or other copyright owners and it is a condition of accessing publications that users recognise and abide by the legal requirements associated with these rights.

- Users may download and print one copy of any publication from the public portal for the purpose of private study or research.

- You may not further distribute the material or use it for any profit-making activity or commercial gain

- You may freely distribute the URL identifying the publication in the public portal 


\title{
Transmission of Multilevel 60 Gbit/s Polarization Multiplexed RZ-D8PSK using only 10 Gbit/s equipment
}

\author{
Jesper Bevensee Jensen, Torger Tokle, Christophe Peucheret and Palle Jeppesen \\ COM•DTU, Technical University of Denmark, Building 345v, DK-2800 Lyngby, Denmark \\ Phone: +45 45253877, Fax: +45 45936581, E-mail:jj@com.dtu.dk
}

\begin{abstract}
By combining differential 8-ary phase shift keying with polarization multiplexing, we present transmission of multilevel modulation with 6 bits per symbol through a $100 \mathrm{~km}$ fiber span with a receiver bit-error-ratio better than $10^{-9}$.

2007 Optical Society of America

OCIS codes: (060.4510) Optical communications
\end{abstract}

\section{Introduction}

The continuous increase in the demand for capacity in optical communication systems has in recent years led to investigations of advanced modulation formats capable of transmitting more than one data bit with each optical pulse. Typically, this is achieved through the use of multiple amplitude levels, multiple phase levels or a combination of the two. Some of the advantages of multilevel modulation formats are higher spectral efficiency and hence better utilization of the available bandwidth and a higher tolerance towards dispersion compared to binary modulation at the same bit rate $[1,2]$.

Numerical investigations of differential 8-ary phase shift keying (D8PSK) have been presented in [3], but so far very few experimental results have been reported. An experimental investigation of the dispersion tolerance of D8PSK has been performed in [4], and transmission results have been reported in [5], however limited to bit error ratios (BER) of the order of $10^{-4}$ to $10^{-5}$.

In this paper, we present for the first time transmission over $100 \mathrm{~km}$ of D8PSK combined with polarization multiplexing (PolMux) with a received BER better than $10^{-9}$. The combination of D8PSK and PolMux results in 6 bits per symbol. The symbol rate used in the experiments was $10 \mathrm{Gbaud}$, resulting in a data rate of $60 \mathrm{Gbit} / \mathrm{s}$.

\section{Principle and experimental set-up}

Figure 1 shows a block diagram of the RZ-D8PSK-PolMux transmitter, the transmission span and the receiver used in the experiments.

Continuous wave (CW) light at a wavelength of $1551 \mathrm{~nm}$ was converted to a $50 \%$ duty-cycle pulse train by a Mach-Zehnder (MZ) modulator, driven by a $10 \mathrm{GHz}$ clock signal at an amplitude equal to the switching voltage $\mathrm{V}_{\pi}$ of the MZ modulator. The RZ pulse train was amplified by an erbium doped fiber amplifier (EDFA) in order to compensate for modulator loss. 8-state phase modulation was added by 3 successive data modulators: a phase modulator (PM) driven by a $2^{7}-1$ bit pseudo random bit sequence (PRBS) data signal with an amplitude equal to $0.5 \mathrm{~V}_{\pi}$ of the PM in order to give a $\pi / 2$ phase shift, a PM driven by a $2^{7}-1$ bit PRBS data signal with an amplitude equal to $0.25 \mathrm{~V}_{\pi}$ of the PM in order to give a $\pi / 4$ phase shift and a Mach-Zehnder modulator driven by an inverted $2^{7}-1$ bit PRBS data signal with an amplitude equal to $2 \mathrm{~V}_{\pi}$ of the modulator, which was biased at a zero transmission point in order to give a $\pi$ phase shift without additional amplitude modulation. Decorrelation of the 3 data signals was ensured by having a difference in optical- and electrical time delays between the modulators. The decorrelations were 61 bits between the $\pi$ and $\pi / 2$ phase shifts and 36 bits between the $\pi$ and $\pi / 4$ phase shifts. Time alignment of the modulations and the RZ pulses was obtained with variable electrical time delays at the drive signals. The resulting signal was then polarization multiplexed to achieve a $60 \mathrm{Gbit} / \mathrm{s}$ RZ-D8PSK-PolMux signal at a symbol rate of 10 Gbaud. Polarization multiplexing was performed by splitting the signal with a $3 \mathrm{~dB}$ fiber coupler, delaying one arm with 2 meters of fiber, and combining the two arms again in a polarizing beam splitter (PBS).

The signal was transmitted through a $100 \mathrm{~km}$ fiber span consisting of alternating spools of $25 \mathrm{~km}$ standard single mode fiber (SMF) with a dispersion of $17 \mathrm{ps} /(\mathrm{nm} \cdot \mathrm{km})$, and $25 \mathrm{~km}$ inverse dispersion fiber (IDF) with a dispersion of $-17 \mathrm{ps} /(\mathrm{nm} \cdot \mathrm{km})$. The optical input power to the span was $15 \mathrm{dBm}$. Out of band amplified spontaneous emission (ASE) noise from the EDFA was suppressed by an optical band-pass filter with a $3 \mathrm{~dB}$ bandwidth of $3 \mathrm{~nm}$. After transmission, the signal was amplified, filtered and split in two by a $3 \mathrm{~dB}$ coupler. One output of the coupler was used for clock recovery, the other was used for data recovery at the amplified receiver.

Clock recovery was obtained by direct detection of the optical RZ signal by a $10 \mathrm{GHz}$ photodetector followed by a narrow band electrical amplifier. 


\section{OWM4.pdf}

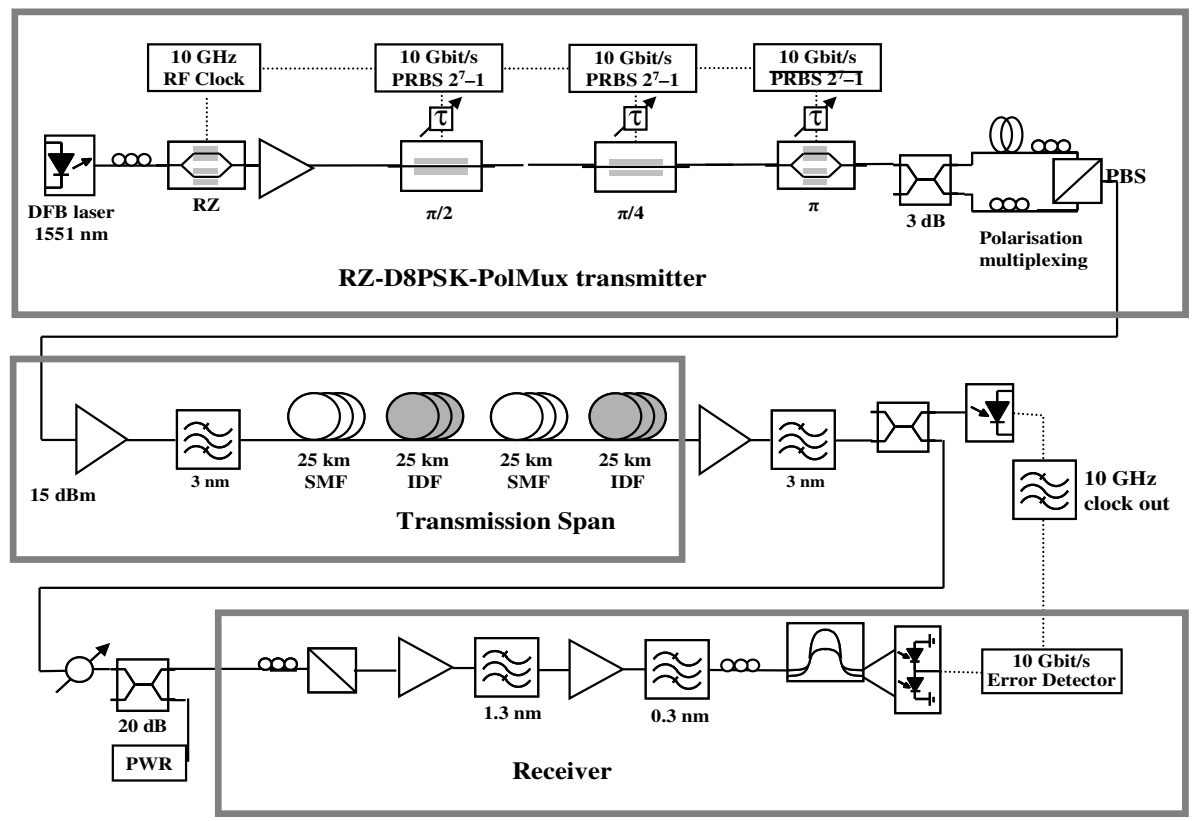

Figure 1. Simplified block diagram of the setup used in the experiments.

After measuring the optical power into the pre-amplified receiver, the signal was polarization de-multiplexed with a PBS and amplified by a two-stage EDFA. Out of band ASE was suppressed by optical band-pass filtering. Demodulation of the phase modulation was performed by a fiber based 1 symbol delay demodulator from ITF Optical Technologies before detection by a pair of balanced photodiodes. Errors were counted using a $10 \mathrm{Gbit} / \mathrm{s}$ programmable error detector.

Four different tributaries can be measured individually by applying a phase off-set of $-3 \pi / 8,-\pi / 8, \pi / 8$ or $3 \pi / 8$ to one arm of the delay demodulator. Two of them (1 and 2) correspond directly to 2 of the 3 D8PSK tributaries. The third D8PSK tributary can be found by performing a logical operation on the two remaining detected tributaries (3a and 3b) [3]. All D8PSK- and polarization tributaries were measured one after the other.

\section{Characterizations and BER performance}

Back to back

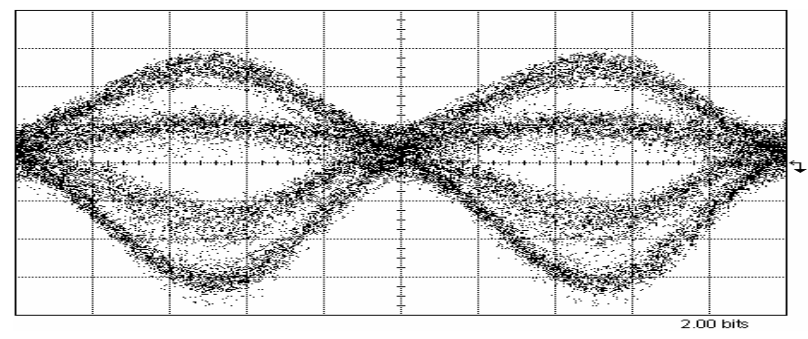

After $100 \mathrm{~km}$ transmission

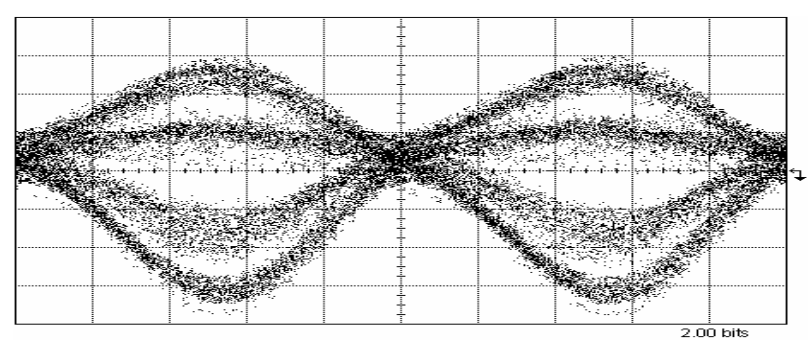

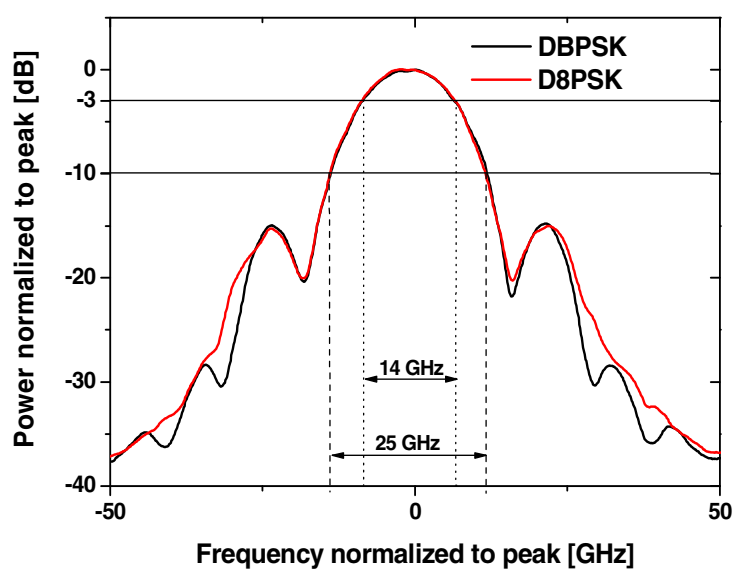

Frequency normalized to peak [GHz]

Figure 2: Left: Eye diagrams. Horizontal scale 20 ps/division

Right: Optical power spectra. Resolution bandwidth $0.1 \mathrm{~nm}$ 


\section{OWM4.pdf}

In figure 2 (left), eye diagrams for the electrical demodulated RZ-D8PSK-PolMux signal before- and after transmission are shown. The 4 levels are a consequence of the 1 bit delay interferometric demodulation. Very little degradation of the eye diagram after transmission is observed.

The optical power spectrum of the signal is shown in figure 2 (right). As a comparison, the optical power spectrum of differential binary phase shift keying-polarization multiplexing (RZ-DBPSK-PolMux) is also shown. This was achieved by turning off the drive signal to the two phase modulators. The $-10 \mathrm{~dB}$ bandwidth of the $60 \mathrm{Gbit} / \mathrm{s}$ RZ-D8PSK-PolMux is only $25 \mathrm{GHz}$, and no increase of the $-10 \mathrm{~dB}$ bandwidth is observed when going from DBPSK to D8PSK. This confirms the ability of multilevel modulation formats to utilize the available bandwidth more efficiently than binary modulation formats.
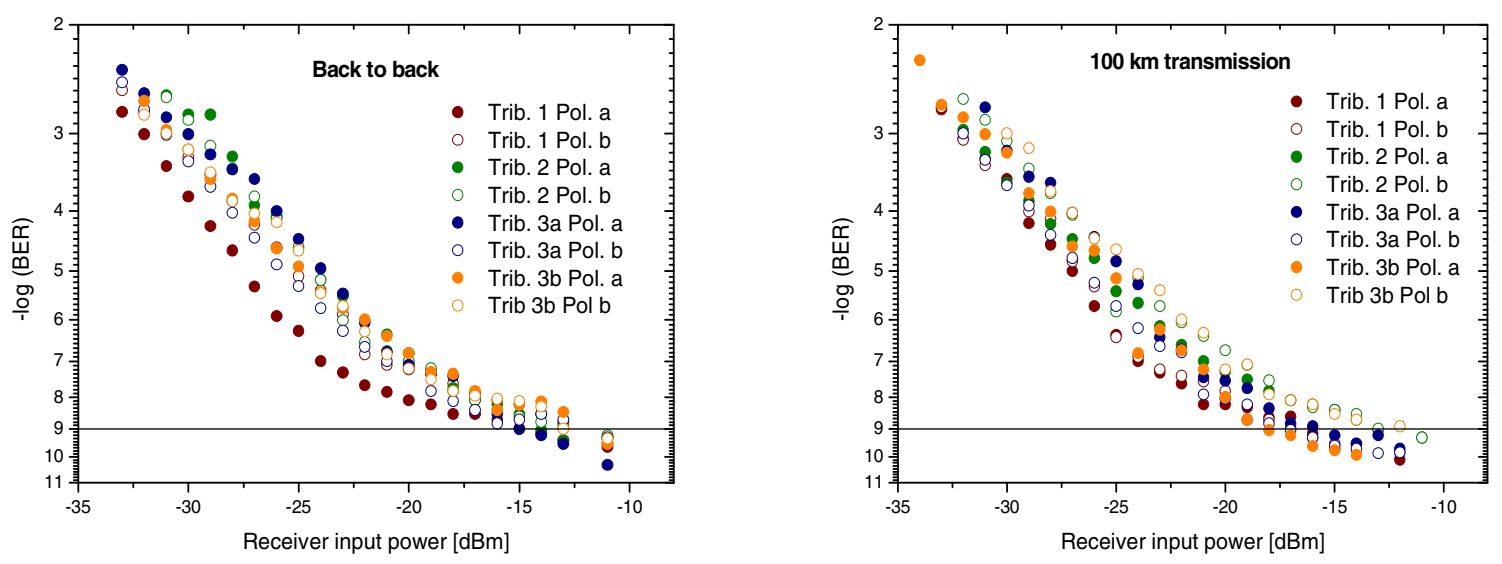

Figure 3. BER measurements back to back and after transmission

BER measurements are plotted in figure 3 for the back to back case (left) and after transmission (right). In all cases, a BER better than $10^{-9}$ was observed. Back to back receiver sensitivity ranged from $-12 \mathrm{dBm}$ to $-15 \mathrm{dBm}$. Receiver sensitivity after transmission ranged from $-12 \mathrm{dBm}$ to $-18 \mathrm{dBm}$. The difference between the measurements of the individual tributaries is caused by instability in the setup due to polarization drift mainly caused by fluctuations in temperature in the laboratory. For the back to back case without polarization multiplexing, receiver sensitivities were all within $2 \mathrm{~dB}$ of each other.

\section{Conclusion}

Optical multilevel RZ-D8PSK-PolMux with 6 bits per symbol has been investigated experimentally. Using only $10 \mathrm{Gbit} / \mathrm{s}$ equipment and a symbol rate of $10 \mathrm{Gbit} / \mathrm{s}$, a bit rate of $60 \mathrm{Gbit} / \mathrm{s}$ was achieved. Measured optical power spectra of $20 \mathrm{Gbit} / \mathrm{s}$ RZ-DBPSK-PolMux and $60 \mathrm{Gbit} / \mathrm{s}$ RZ-D8PSK-PolMux have confirmed the high bandwidth utilization expected from multilevel modulation formats. Transmission of RZ-D8PSK-PolMux over a $100 \mathrm{~km}$ fiberspan with a received BER better than $10^{-9}$ was performed for the first time to our knowledge.

\section{References}

1. J. B. Jensen et al, Proceedings of LEOS 2006, 2006

2. K. Sekine et al, Electron. Lett. 41 (7) (2005), pp 430-432

3. C. Kim et al, Optics Express 41 (15) (2004), pp. 3415-3421, 2004

4. M. Serbay et al, Proceedings of LEOS 2005, pp. 483-484, 2005

5. C. Kim et al, Optics Express 13 (11) (2005), pp. 4044-4049, 2005 